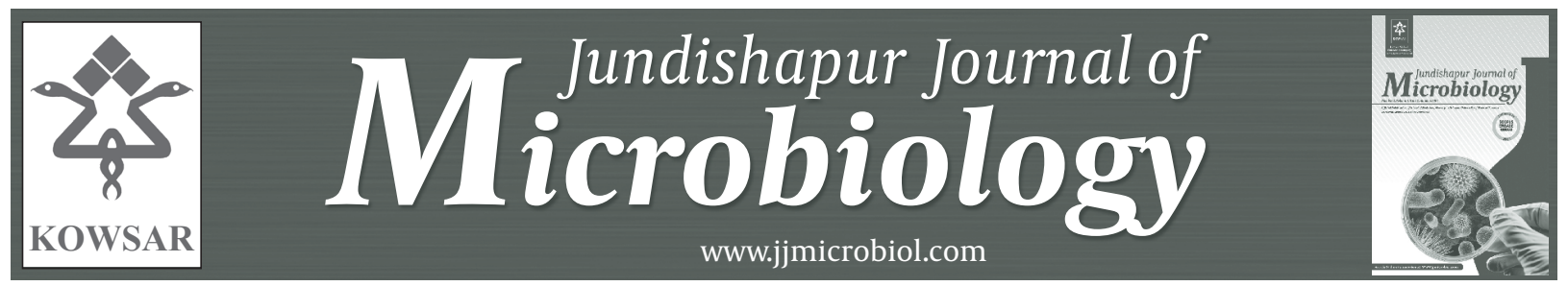

\title{
Airborne Fungi in Tabriz, Comparing Airborne and Clinical Samples of A. fumigatus (2011), Survey and Literature Review
}

\author{
Abdolhassan Kazemi ${ }^{1}$, Ehssan Ahmadpour ${ }^{1}$, Behroz Naghili ${ }^{1}$, Ali Zarei Mahmoudabadi ${ }^{2}$, \\ Abbasali Jafari ${ }^{3,{ }^{*}}$, Amin Mousavi Ayatollahi ${ }^{4}$ \\ ${ }^{1}$ Infection and Tropical Disease Research Center, Tabriz University of Medical Sciences, Tabriz, IR Iran \\ 2 Department of Medical Mycology, and Infectious and Tropical Diseases Research Centre, Ahvaz Jundishapur University of Medical Sciences, Ahvaz, IR \\ Iran \\ ${ }^{3}$ Department of Medical Mycology, School of Medicine, Shahid Sadoughi University of Medical Sciences, Yazd, IR Iran \\ ${ }^{4}$ Department of Medical Mycology, School of Medicine, Kerman University of Medical Sciences, Kerman, IR Iran \\ *Corresponding author: Abbasali Jafari, Department of Medical Mycology, School of Medicine, Shahid Sadoughi University of Medical Sciences, Yazd, IR \\ Iran. Tel.: +98-3518228717, Fax: +98-3518228717, E-mail: Jafariabbas@yahoo.co.in.
}

\section{A B S T R A C T}

Background: Air contamination with fungal spores and the presence of these spores on respiratory tract, especially in industrialized cities with contaminated air, can play an important role on the occurrence of respiratory and coetaneous mycoses, asthma and allergic reactions. This survey was carried out to determine the prevalence of different fungal spores in the atmosphere of Tabriz district.

Objectives: The present study aimed to detect fungal air spores in Tabriz environments, and to compare the environmental samples of Aspergillus fumigatus with the clinical isolated samples of this fungus, due to the importance of the dangers of A. fumigatus for public health, particularly for the immunocompromised patients.

Materials and Methods: During this survey, the presence of air fungal spores was analyzed using settle plate and prepared culture in Sabouraud's dextrose agar. Prior identifications were performed using macroscopic characters, and direct microscopy. 262 samples were collected from different areas of the atmosphere of Tabriz district within all four seasons of the year. Fungal colonies were isolated from all air samples and identified using macroscopic and microscopic characters, and slid culture.

Results: The main isolated fungal spores from the atmosphere of Tabriz district were Penicillium Sp. (36.6\%), Cladosporidium Sp. (26.8\%) and Aspergillus Sp. (23.6\%).

Conclusions: The presence of fungal spores in the atmosphere as a part of air pollution can cause significant problems for human health, particularly in the respiratory tracts.

Keywords: Fungi; Spores, Fungal; Tabriz; Aspergillus fumigatus

Copyright $\odot$ 2013, Ahvaz Jundishapur University of Medical Sciences; Published by Kowsar Corp.

Article type: Research Article; Received: 04 Apr 2012; Revised: 19 Jun 2012; Accepted: 09 Jul 2012; Epub: 01 Jun 2013 ; Ppub: 2013 Jun

Implication for health policy/practice/research/medical education:

Due to the importance of fungal spores on the safety of susceptible people, studying fungal spores' presence and the type of spores can give beneficial ideas for health and hygiene programming.

-Please cite this paper as:

Kazemi A, Ahmadpour E, Naghili B, Zarei Mahmoudabadi A, Jafari A, Mousavi Ayatollahi A. Airborne Fungi in Tabriz, Comparing Airborne and Clinical Samples of A. fumigatus (2011), Survey and Literature Review. Jundishapur J Microbiol. 2013;6(4):e4997. DOI: $10.5812 / j j m .4997$.

Copyright (C) 2013, Ahvaz Jundishapur University of Medical Sciences; Published by Kowsar Corp.

This is an Open Access article distributed under the terms of the Creative Commons Attribution License (http://creativecommons.org/licenses/by/3.0), which permits unrestricted use, distribution, and reproduction in any medium, provided the original work is properly cited. 


\section{Background}

A large body of evidence has demonstrated that human urbanization has a relationship with the increasing exposure to airborne microorganisms that may result in a variety of adverse health effects, and can particularly lead to allergic symptoms (1-3). The major allergic manifestations include asthma, rhinitis, hypersensitivity pneumonitis, and other diseases such as immunotoxic diseases (e.g. sick building syndrome "SBS") (4).

Respiratory abnormalities, diseases, and symptoms which could be caused by exposure to fungal spores, include asthma and asthma development, exacerbation of asthma, hypersensitivity pneumonitis, wheeze, cough, dyspnea (shortness of breath), nasal and throat symptoms, nose running and respiratory mycoses. In addition to the above diseases and symptoms, rhinosinusitis and sarcoidosis in water-damaged buildings occupants are also drawing more medical attention $(5,6)$. Moreover, the increase in respiratory allergy parallels an increase in air pollution. The most abundant air pollutants such as sulphur dioxide, nitrogen dioxide, ozone, microbial and fungal microflora (7-9) in urban areas with high levels of vehicle traffic are a remediable issue.

The presence of allergen particles in fungal spores such as ASPF6, ASPF4, ASPF2, Pen ch 18, 1-3beta-D-glucan, Rho m2with peptide fragments such as Lys89, phe91, and Lys90 enumerate allergic segments that irritate immune response, and causes a IgE serum level increase in allergic people. Therefore, fungal microflora can have an important effect on the respiratory health of people $(10,11)$.

So far the studies on the types and the count of aerial bio-microflora have shown that Aspergillus Sp., Cladosporidium Sp. and Penicillium Sp. have the highest percentage in aerial microflorain city environments $(7,12,13)$. In Iran, according to the results of the previous researches, Penicillium Sp., Chrysosporium Sp., Cladosporidium Sp., Candida Sp., Fusarium Sp. and Alternaria Sp. Spores have been postulated as the highest fungal spores in city atmospheres (14-17). Also some studies indicated that there is relationship between the presence of these fungal spores and mycoses on the area in question (18).

\section{Objectives}

Accordingly, regarding the importance of the subject, we decided to survey the different types of fungal microflora in the atmosphere of Tabriz, and the purpose was to prove the presence of fungal spores and their species in the region's air.

\section{Materials and Methods}

\subsection{Sample Collection and Culture}

Using settle plate (open plate method), sampling was performed from the air in 262 plates containing Sabouraud's Dextrose Agar (SDA) (Oxiod Ltd., Basingstoke, Hampshire, U.K.) medium during a 12-month period, and from different parts of the city. The triplicate sampling from different locations (northern, southern, western, eastern and also central regions) of the city was carried out on the same days every week during the survey period (Figure 1).

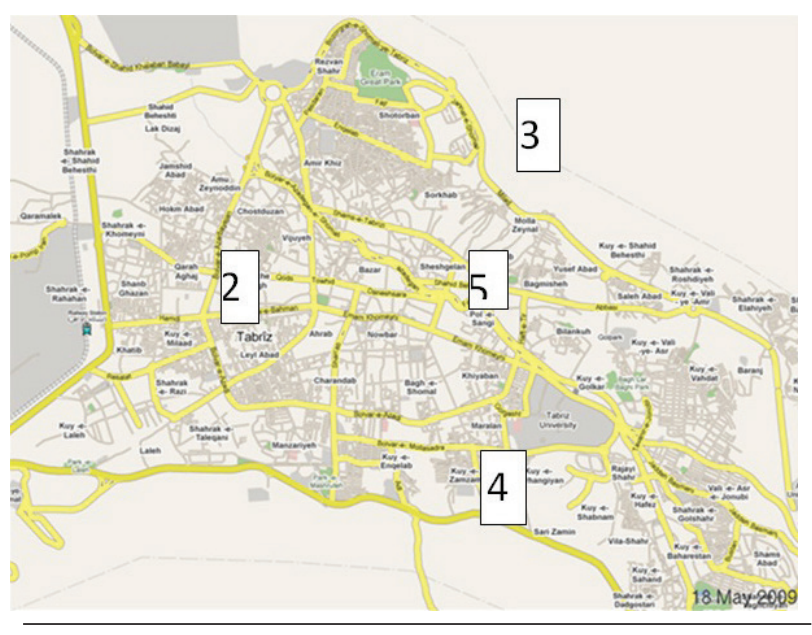

Figure 1. Descriptive Map of Sampling Areas

The presence and amounts of spores in the air were assessed by exposing a Petri dish containing media to air for 15 minutes. Plates were incubated in $24^{\circ} \mathrm{C}$ for at least twenty-one days. During incubation, the plates were reviewed for the growth of fungal colonies once every 24 hours. The total number of fungal colonies counted on the plates was between 1 to 5 colonies (CFUs).

All plates survived for macroscopic and microscopic characteristics. The growth process of fungi in each of the plates was then monitored closely. The suspected fungi with definitive diagnosis by the use of the mentioned methods were then identified by performing slide culture by Riddle method. Regarding the standard protocols, the pathogenic genomic DNAs of A. fumigatus were obtained from patients' septum, and Bronchoalveolar lavage (BAL) with approved pulmonary aspergillosis according to their clinical symptoms and paraclinical findings.

\subsection{Molecular Assay}

To compare the isolated pathogenic A. fumigatus from patients with the plates' isolated A. fumigatus, DNA extraction from both samples were carried out prior to PCR reaction. PCR was performed with the degenerated primers that were solely designed for a highly conserved region of A.fumigatus' genome, using bioinformatics tools (multiple alignments). The degenerated primers used were as follows:

Primer Sequence 


\section{Forward5' GAY TGG TRG CTI AGY CCI GA 3'}

Reveres5' AAR AAY TGR TTY TCI ATR TAC 3'

PCR reactions (total volume of $100 \mu \mathrm{l}$ ) were carried out with genomic DNAs of both environmental and pathogenic A. fumigatus using the standard protocols (10 $\mu$ l of 10x PCR buffer, $1 \mu \mathrm{l}$ from each primers, $1 \mu \mathrm{ldNTP}, 0 / 5 \mu \mathrm{l}$. fumigatus genomic DNA, $1 \mu$ TTaq DNA polymerase, $85.5 \mu \mathrm{l}$ DSW). PCR reactions with each primer set (Perkin-Elmer, Applied Biosystems, Warrington, Cheshire, U.K), were optimized (catalyzed) by carrying out the reactions with $\mathrm{MgCl} 2$ concentrations in the range of 4 to $6 \mathrm{mM}$ (19). The optimal magnesium concentration was found to be 4 $\mathrm{mM}$. The PCR conditions for the above primers are shown below.

\subsection{PCR Conditions}

\section{$3 \min 94^{\circ} \mathrm{C} x 1$}

$1 \min 94^{\circ} \mathrm{C}, 2 \min 48^{\circ} \mathrm{C}, 3 \min 72^{\circ} \mathrm{C} \times 29$

$1 \min 94^{\circ} \mathrm{C}, 2 \min 48^{\circ} \mathrm{C}, 7 \min 72^{\circ} \mathrm{C} \mathrm{x1}$

PCR reaction produced a single product of ca. $1600 \mathrm{bp}$

Figure 2. Gel Electrophoresis of PCR Products Using Degenerate Primers

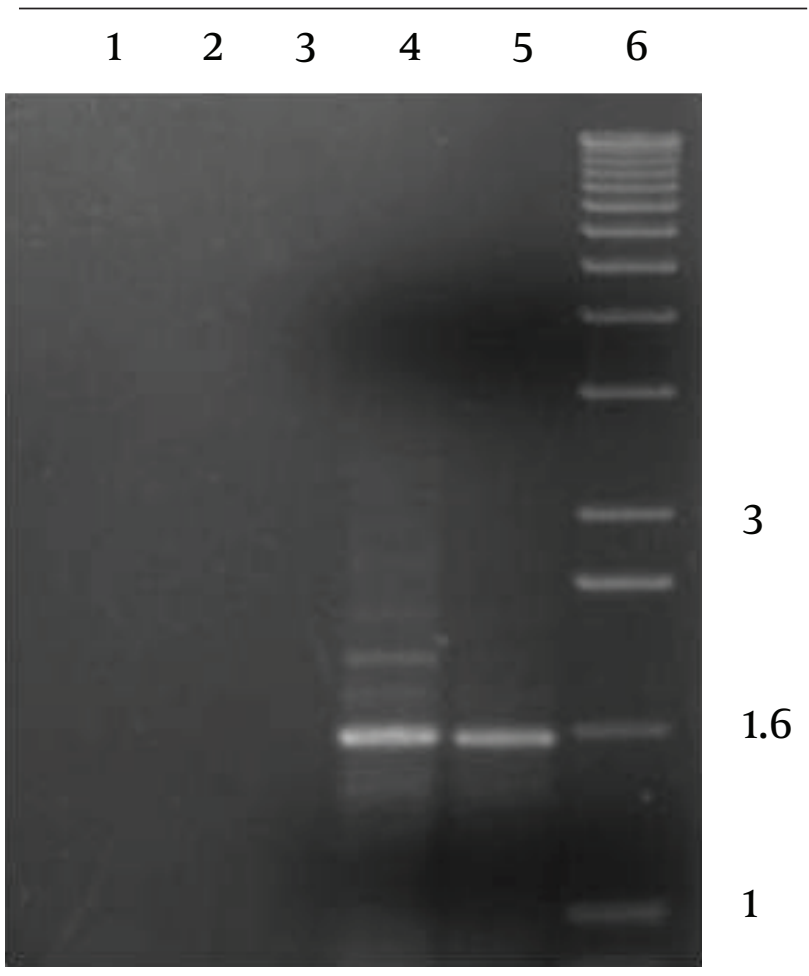

PCR products were visualized by gel electrophoresis. Lanes 1, 2 and 3 show the results of the PCR in the absence of genomic DNA (lane 1) or with the primer (lanes $2 \& 3$ ). Lanes 4 and 5 show the PCR products obtained from the primers, and both used genomic DNAs of environmental and pathogenic A. fumigatus respectively. Lane 6 shows the molecular weight marker, with band sizes $(\mathrm{Kb})$ indicated at the right. The +sign indicates the direction of the positive electrode during electrophoresis. with both pathogenic and environmental A. fumigatus' genomic DNAs, which was as predicted based on the genomic sequences (Figure 2).The implemented control reactions with either the individual primers or with no template DNA, did not produce any amplification products.

\section{Results}

After the determination of fungal genus using macroscopic/microscopic characteristics and counting the number of fungal colonies, the following results were obtained: Due to the percentage of each fungal genus, the most identified fungi were: Penicillium Sp., Cladosporidium Sp. and Aspergillus Sp. respectively as showed in Table 1. Also the PCR reaction products showed that there are strong genomic similarities between the environmental isolated and pathogenic A. fumigatus, which were obtained from the clinical samples of patients with pulmonary aspergillosis.

\begin{tabular}{lll}
\hline \multicolumn{2}{l}{ Table 1. Colony Count and Percentage of the Identified Fungi } \\
\hline Fungi & Percentage & Colony Count \\
\hline Penicillium Sp. & 39.6 & 104 \\
\hline Cladosporidium Sp. & 26.8 & 70 \\
\hline Aspergillus Sp. & 23.6 & 62 \\
\hline Tichoderma Sp. & 5.1 & 14 \\
\hline Yeast & 2.8 & 4 \\
\hline Chrysosporium Sp. & 0.7 & 2 \\
\hline Fusarium Sp. & 0.7 & 2 \\
\hline Alternaria Sp. & 0.7 & 2 \\
\hline Acremonium Sp. & 0.7 & 2 \\
\hline Total & 100 & 262 \\
\hline
\end{tabular}

\section{Discussion}

Fungi can both degrade the organic materials and structures of their colonies, and contribute to the appearance of symptoms and diseases in the inhabitants of contaminated homes, hospitals, factories, etc. $(8,9)$. Citizens in city environments are not only at risk of harm to their health through environmental degradation as a result of the worsening air pollution problems such as fungal spores, but are also constantly threatened by emerging and recurring asthma, rhinitis, bronchopulmonary disorders, mycoses and hypersensitivity pneumonitis epidemics $(2,3)$.

It is notable that fungal spores are a significant component of bioaerosol, and are also considered to act as a marker of the level of atmospheric bio-pollution. Therefore, better understanding of this phenomenon demands a detailed survey of the airborne particles. Some studies have emphasized that fungal spores' concentration can 
be a scientific indicator of indoor air quality, and that it is necessary to deepen the studies of indoor atmospheres in order to promote the air quality, the health/hygiene, and a better consideration of the biology of indoor fungi $(8,9)$.

Tabriz (metropolis in the northwest of Iran), with a high industrialization pace and population growth, and its consequent closeness to the hypothetical epicenters of disease transmission, offers a unique opportunity on testing environmental air contamination with fungal spores. According to the obtained results, various species of Cladosporidium Sp., Fusarium Sp. and Aspergillus SP., after Penicillium Sp., contain the highest percentage of fungal spores in the studied area. Also in some other studies about fungal air pollution, Aspergillus Sp. and Penicillium Sp. were the most abundant fungal spores' type with a yearly mean percentage that represented $65 \%$ of the total, followed by Cladosporium Sp. (12).

According to the previous studies on this subject, Penicillium Sp., Chrysosporium Sp., Cladosporidium Sp., Candida Sp., Alternaria Sp.Fusarium Sp., Ulocladium Sp., Geotrichum Sp., and Zygomycota (Mucor \& Rhizopus spp.) were the most common fungal air flora in various regions of Iran. The studies of fungal air spores in different cities of Iran including Ahvaz $(20,21)$ Isfahan $(14,22)$, Ardestan (23), Shahrekord (24), Qeshm island (25), Kerman (26), Qom (27), Qazvin (28), Gonabad (29), Babol city and Babolkenar forest (30), Yazd (31), Semnan (32), Sari (33), Urmia (34), Tabriz (18) and Lorestan province (35) have mainly shown similar results, as mentioned above.

Some studies also indicate a relationship between the presence of these fungal spores and mycoses in the studied areas $(14,21,32,35)$. Similar studies in the neighboring (or close) countries to Iran such as Turkey (36), Pakistan (37) and India (38) also demonstrated the presence of the same fungi in their atmosphere with some minor exceptions. For example in Turkey (36) Chrysosporium sp., Conidiobolus sp., Cladothecium sp., and in Karachi (Pakistan) (37) Periconia sp., Curvularia sp., and Stemphylium sp., have been isolated in addition to the usual fungal air flora. In Kolkata (India), more than 50 fungal taxa of airborne fungal spores were isolated from the air, among which at least 15 taxa were considered as allergenic fungi (17).

Fungal spores inhalation or other kinds of exposure to these fungi can cause respiratory diseases or illnesses including asthma, cutaneous and visceral mycoses such as fungal keratitis, otomycosis, and other various clinical symptoms of aspergillosis and penicilliosis $(17,18)$. Among the above mycoses, pulmonary infection with Aspergillus and Penicillium sp., (as two etiologic agents of life threatening infections) is very prevalent, particularly amongst immunocompromised patients as well as chemotherapy treated patients, radiotherapy, HIV+, and bone marrow recipients (38-42).

Also, in this study, a comparison between the environmental and clinical samples of A. fumigatus using molec- ular assay showed a similarity among both samples. This finding could be considered as evidence on the source of airborne mycoses due to inhalation of environmental fungal spores (41). Exposure to these kinds of environmental fungal spores could lead to deep mycoses, such as different types of pulmonary aspergillosis (IA, ABPA, CBPA, aspergilloma) and sinusitis, particularly among immunocompromised patients with serious consequences $(15,43)$.

The results of this study can be beneficial for the management of public health surveillance particularly on asthma, rhinitis, bronchopulmonary disorders and cutaneous mycoses in the region. It may attract the attention of the regional health systems managers towards the several risks to the health of the region's population when considering environmental protection and management in the context of economics, urban, and infra structural developments. This is the first study in Tabriz area to examine the fungal air pollution from an environmental health perspective. However, more studies are needed to further document its efficacy, and also perform a costbenefit analysis of these services.

\section{Acknowledgements}

The authors sincerely thank Dr. Behroz Naghili (Infectious Disease \&amp;amp; Tropical Medicine Dept. of Tabriz University of Medical Sciences) for his useful ideas during the survey.

\section{Financial Disclosure}

There is no Financial Disclosure for this survey.

\section{Funding/Support}

This study was financially supported by Infection and Tropical Disease Research Center, Tabriz University of Medical Sciences, Tabriz, Iran.

\section{Authors' Contribution}

None declared.

\section{References}

1. Gholizadeh MH, Farajzadeh M, Darand M. The Correlation Between Air Pollution and Human Mortality in Tehran. Hakim Res J. 2009;12(2):65-71.

2. Hedayati MT, Mayahi S, Denning DW. A study on Aspergillus species in houses of asthmatic patients from Sari City, Iran and a brief review of the health effects of exposure to indoor Aspergillus. Environ Monit Assess. 2010;168(1-4):481-7.

3. Wong CM, Thach TQ, Chau PY, Chan EK, Chung RY, Ou CQ, et al. Part 4. Interaction between air pollution and respiratory viruses: time-series study of daily mortality and hospital admissions in Hong Kong. Res Rep Health Eff Inst. 2010(154):283-362.

4. Gubernskii Iu D, Nel'nikova AI, Kalinina NV, Chuprina OV. [Fungal contamination of dwelling and public buildings: hygienic aspects]. Gig Sanit. 2010(5):26-8.

5. Fairs A, Wardlaw AJ, Thompson, Jr, Pashley CH. Guidelines on ambient intramural airborne fungal spores. J Investig Allergol Clin Immunol. 2010;20(6):490-8. 
6. Jones R, Recer GM, Hwang SA, Lin S. Association between indoor mold and asthma among children in Buffalo, New York. Indoor Air. 2011;21(2):156-64.

7. Park JH, Cox-Ganser JM. Mold exposure and respiratory health in damp indoor environments. Front Biosci (Elite Ed). 2011;3:757-71.

8. Raphoz M, Goldberg MS, Garneau M, Heguy L, Valois MF, Guay F. Associations between atmospheric concentrations of spores and emergency department visits for asthma among children living in Montreal. Arch Environ Occup Health. 2010;65(4):201-10.

9. Straus DC. The possible role of fungal contamination in sick building syndrome. Front Biosci (Elite Ed). 2011;3:562-80.

10. Docampo S, Trigo MM, Recio M, Melgar M, Garcia-Sanchez J, Cabezudo B. Fungal spore content of the atmosphere of the Cave of Nerja (southern Spain): diversity and origin. Sci Total Environ. 2011;409(4):835-43.

11. Reponen T, Singh U, Schaffer C, Vesper S, Johansson E, Adhikari A, et al. Visually observed mold and moldy odor versus quantitatively measured microbial exposure in homes. Sci Total Environ. 2010;408(22):5565-74

12. Cabral JP. Can we use indoor fungi as bioindicators of indoor air quality? Historical perspectives and open questions. Sci Total Environ. 2010;408(20):4285-95.

13. Cecchi L, D'Amato G, Ayres JG, Galan C, Forastiere F, Forsberg B, et al. Projections of the effects of climate change on allergic asthma: the contribution of aerobiology. Allergy. 2010;65(9):1073-81.

14. Chadeganipour M, Shadzi S, Nilipour S, Ahmadi G. Airborne fungi in Isfahan and evaluation of allergenic responses of their extracts in animal model. Jundishapur JMicrobiol. 2011;3(4):155-160.

15. Knutsen AP, Bush RK, Demain JG, Denning DW, Dixit A, Fairs A, et al. Fungi and allergic lower respiratory tract diseases.J Allergy Clin Immunol. 2012;129(2):280-91.

16. Mihinova D, Pieckova E. Moldy buildings, health of their occupants and fungal prevention. Bratisl Lek Listy. 2012;113(5):314-8.

17. Pelaez T, Munoz P, Guinea J, Valerio M, Giannella M, Klaassen CH, et al. Outbreak of invasive aspergillosis after major heart surgery caused by spores in the air of the intensive care unit. Clin Infect Dis. 2012;54(3):e24-31.

18. Kazemi A, Argani H. Study on fungi microflora of Tabriz Imam Reza hospital dialysis and renal transplantation wards: Tabriz Uni Med Sci. 2007

19. ARIADNE First Summer School Workshop. 2010; Available from: http://www.carlsberglab.dk/professors/Wendland/collaborators/PublishingImages/SS-I_Protocols.pdf.

20. Hariri AR, Ghahary A, Naderinasab M, Kimberlin C. Airborne fungal spores in Ahwaz, Iran. Ann Allergy. 1978;40(5):349-52.

21. Rafiei A, Hemadi A, Hamzehlooie F. Determination of fungal colonization among burn patients reffered to Taleghani HospitalAhvaz. Iran JInfect Dis Trop Med. 2006.

22. Shadzi S, Zahraee MH, ChadeganiPour M. Incidence of airborne fungi in Isfahan, Iran. Mycoses. 1993;36(1-2):69-73.

23. Kachuei Reza, Emami Masoud, Geramishoar Mohsen. Surveying the airborne pathogenic fungi in desert area of Ardestan town trip. KAUMS J ( FEYZ ). 2004;8(1):43-50.

24. Ebrahimi A, Karimi S, Lotfalian S, Majidi F. Allergenic fungi in deteriorating historic objects of Shahrekord Museum, in Iran. Jundishapur J Microbiol. 2011;4(4):261-265.

25. Barati B, GhariI M, Sorouri R. Isolation and Characterization of Bacteria and Fungi in Ambient Air of Qeshm Island. Med J Hormozgan Uni. 2009;13(2):101-108.

26. Arab N, Ghaemi F. Airborne Fungi Spores in Different Wards of Hospitals Affiliated to Kerman University of Medical Sciences. J Kerman Univ Med Sci. 2006;13(4):247-256.

27. Azizifar M, Jabbari H, Naddafi K, Nabizadeh R, Tabaraie Y, Solg A A qualitative and quantitative survey on air-transmitted fungal contamination in different wards of Kamkar Hospital in Qom, Iran, in 2007. Qom Univ Med Sci J. 2009;3(3):Pe25-Pe30.
28. Aghamirian MR, Jahani Hashemi H. Survey of airborne fungi spores in Qazvin (Mar-Jun 2007). J Qazvin Univ Med Sci. 2010;14(1):65-70.

29. Khosravi AR, Haghighi M, Bahonar A. The study of air flora of Gonabad city for allergenic fungi in summer and in spring. Ofogh-e-Danesh J. 2006;12(3):10-16.

30. Shokri Hojatollah, Khosravi Alireza, Naseri Ali, Ghiyasi Maryam, Ziyapoor Seyed Peyman. Common environmental allergenic fungi causing respiratory allergy in North of Iran. Iran J Vet Med. 2010;3.

31. Jafari Nadoushan AA, Aminipour MR, Ahmadieh MH, Mirzaei farzaneh MZ, Niknazar H, Baghaei A. The Rate of Airborne Fungal Contamination in Yazd Textile Factories In 2007. J Kerman Univ Med Sci. 2010;17(4):337-345.

32. Nabavi M, Ghorbani R, Farzam V. Prevalence of Mold Allergy in Asthmatic Patients of Less than 18 Years Old in Semnan. J Kerman Univ Med Sci. 2010;17(4):328-336.

33. Hedayati MT, Mayahi S, Aghili SR. Survey of spesific IgE to allergenic fungi among asthmatic patients in Sari. J Mazandaran Uni Med Sci. 2003;16:81-8.

34. Afshar yavari SH, Diba K. The Assessment of Bacterial and Fungal Flora of Operating Rooms In Urmia Medical Universiyt Hospitals. JUrmia Univ Med Sci. 2004.

35. Noruzi H, Ebrahimi A, Alavi Taze Abad SH. Alternaria Sp: A life treated fungi in Lorestan provance autmospher. The 14th iranan congress on infectious disease and tropical medicine; 2005.13 p.

36. Ovet H, Ergin C, Kaleli I. [Investigation of mold fungi in air samples of elementary schools and evaluation of allergen-specific IgE levels in students' sera]. Mikrobiyol Bul. 2012;46(2):266-75.

37. Hasnain SM, Akhter T, Waqar MA. Airborne and allergenic funga spores of the Karachi environment and their correlation with meteorological factors. J Environ Monit. 2012;14(3):1006-13.

38. Larbcharoensub N, Aroonroch R, Kanoksil W, Leopairut J, Nitiyanant P, Khositseth A, et al. Infection-associated hemophagocytic syndrome among patients with dengue shock syndrome and invasive aspergillosis: a case series and review of the literature. Southeast Asian J Trop Med Public Health. 2011;42(5):1106-12.

39. Brenier-Pinchart MP, Coussa-Riviere L, Lebeau B, Mallaret MR, Bulabois CE, Ducki S, et al. Mobile air-decontamination unit and filamentous fungal load in the hematology ward: how efficient at the low-activity mode? Am J Infect Control. 2009;37(8):680-2

40. Hopkins CC, Weber DJ, Rubin RH. Invasive aspergillus infection: possible non-ward common source within the hospital environment. J Hosp Infect. 1989;13(1):19-25.

41. Leenders AC, van Belkum A, Behrendt M, Luijendijk A, Verbrugh HA. Density and molecular epidemiology of Aspergillus in air and relationship to outbreaks of Aspergillus infection. J Clin Microbiol.1999;37(6):1752-7.

42. Petrova NA, Kliasova GA, Funygina LP. [Prevalence of mycelial fungi in hematological hospital]. Ter Arkh. 2003;75(7):58-63.

43. Gargani Y, Bishop P, Denning DW. Too many mouldy joints - marijuana and chronic pulmonary aspergillosis. Mediterr J Hematol Infect Dis. 2011;3(1). 